\title{
2020 Virtual MRS Spring/Fall Meeting \& Exhibit first of its kind for Society
}

Tor nearly 50 years, researchers from
around the world have converged in Boston for the Materials Research Society (MRS) Fall Meeting. This fall, the materials community will come together once again, in a new format indicative of our times. Because of the state of the COVID-19 pandemic in the United States and its impact on our daily lives worldwide, MRS will convene the joint 2020 Virtual MRS Spring/Fall Meeting \& Exhibit, scheduled for November 27December 4, as a fully virtual event.

The 2020 MRS Spring Meeting Chairs are Qing Cao, University of Illinois at Urbana-Champaign; Miyoung Kim, Seoul National University; Rajesh Naik, Air Force Research Laboratory; James M. Rondinelli, Northwestern University; and Hong Wang, Southern University of Science and Technology. The 2020 MRS Fall Meeting Chairs are Michael E. Flatté, The University of Iowa; Michael P. Rowe, Toyota Research Institute of North America; Sabrina Sartori, University of Oslo; Prasad Shastri, University of Freiburg; and Chongmin Wang, Pacific Northwest National Laboratory.

\section{Technical sessions}

Five topical clusters for Spring 2020 will be featured during the virtual meeting: Characterization and Theory; Energy, Storage and Conversion; Soft Materials and Biomaterials; Electronics and Photonics; and Nanoscale and Quantum Materials. Eight topical clusters for Fall 2020 will be featured during the virtual meeting: Broader Impact; Electronics and Optics; Energy; Flexible, Wearable Electronics,
Textiles and Sensors; Materials Theory, Characterization and Data Science; Nanomaterials and Quantum Materials; Soft Materials and Biomaterials; and Structural and Functional Materials. The Symposium X Frontiers of Materials Research will feature presentations aimed at a broad audience and on topics at the forefront of research in materials science and engineering. To complement the symposia, Tutorial Sessions will provide detailed information on areas of research, and the Exhibit will showcase products and services of interest to the scientific community.

\section{Award winners \\ Von Hippel Award}

Cato Laurencin (Chemical and Biomolecular Engineering, University of Connecticut, USA). "For pioneering work in

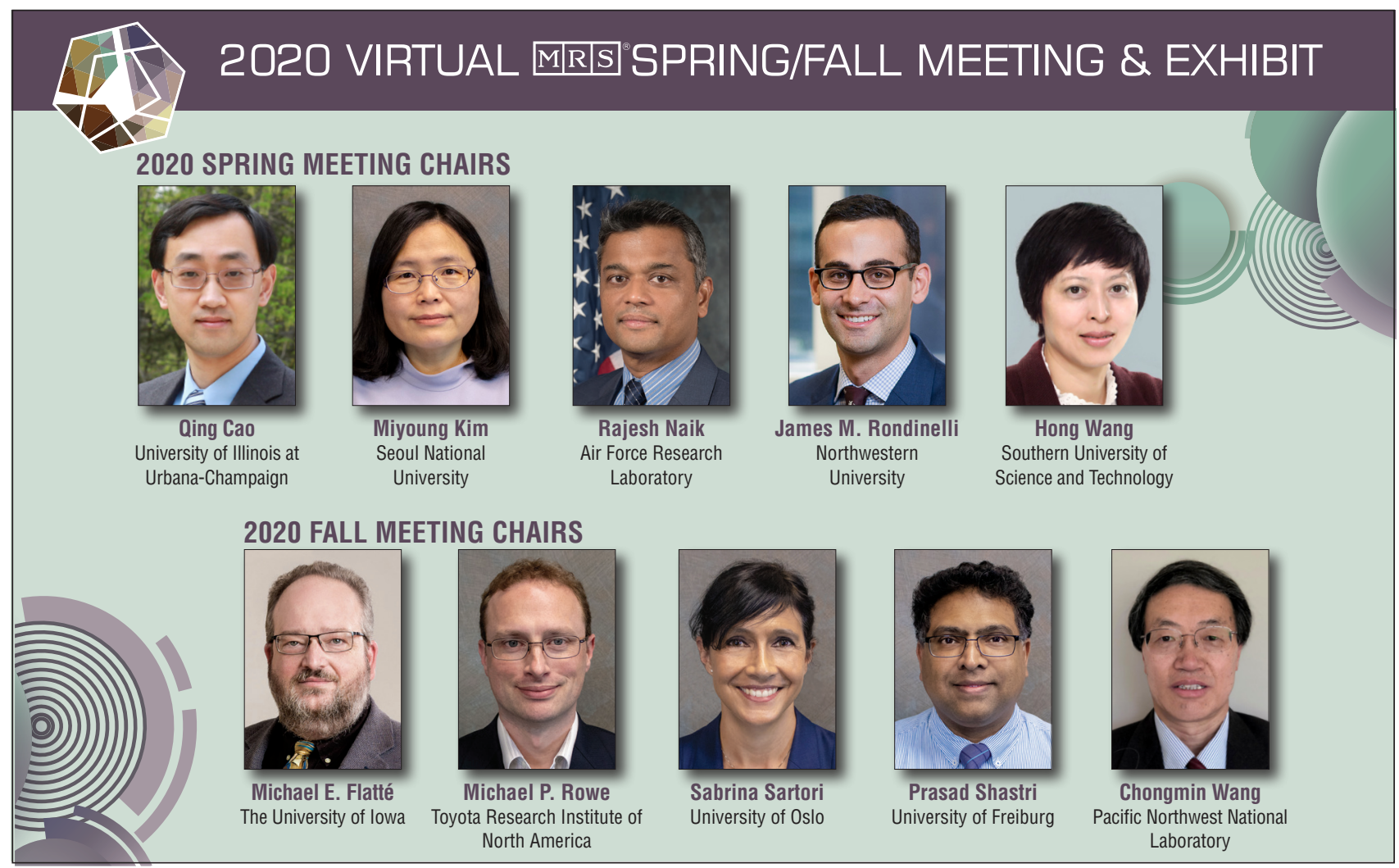


engineering of musculoskeletal tissues, for extraordinary work guiding technology and science policy, and for promoting ethnic diversity and excellence in science."

\section{David Turnbull Lectureship}

Sossina Haile (Materials Science and Engineering, Northwestern University, USA)."For fundamental contributions to the electrochemical and thermochemical materials science that advance sustainable energy, for her commitment to the broader international materials community and for being an inspiring colleague and passionate mentor."

\section{MRS Medal}

Yi Cui (Stanford University, USA) and Linda Nazar (Waterloo Institute for Nanotechnology and the Department of Chemistry, University of Waterloo, Canada). "For outstanding contributions to advanced materials design, synthesis and characterization for energy storage, particularly Li battery technologies."

\section{Materials Theory Award}

Jean-Luc Bredas (Department of Chemistry and Biochemistry, The University of Arizona, USA). "For seminal theoretical contributions to the design and understanding of novel molecules and materials in the fields of organic electronics and photonics."

\section{MRS Nelson "Buck" Robinson Science and Technology Award for Renewable Energy}

Aditya Sadhanala (Centre for Nano Science and Engineering, Indian Institute of Science, India). Sadhanala was selected for his excellent scientific discovery, dedicated effort to enhancing educational opportunities in remote areas of India and Africa, and advocating for renewable energy adoption. Through his outreach efforts in India, he worked with the Laya Foundation NGO(non-governmental organization) to develop and deploy electricity generators powered by dynamos in cookstove chimneys and low-cost solar panels. Finally, to give young students the opportunity to interact with scientists, he and several colleagues founded VIGYANshaala (Vision India: GenY Applied Science Network) and showcased science to 6000

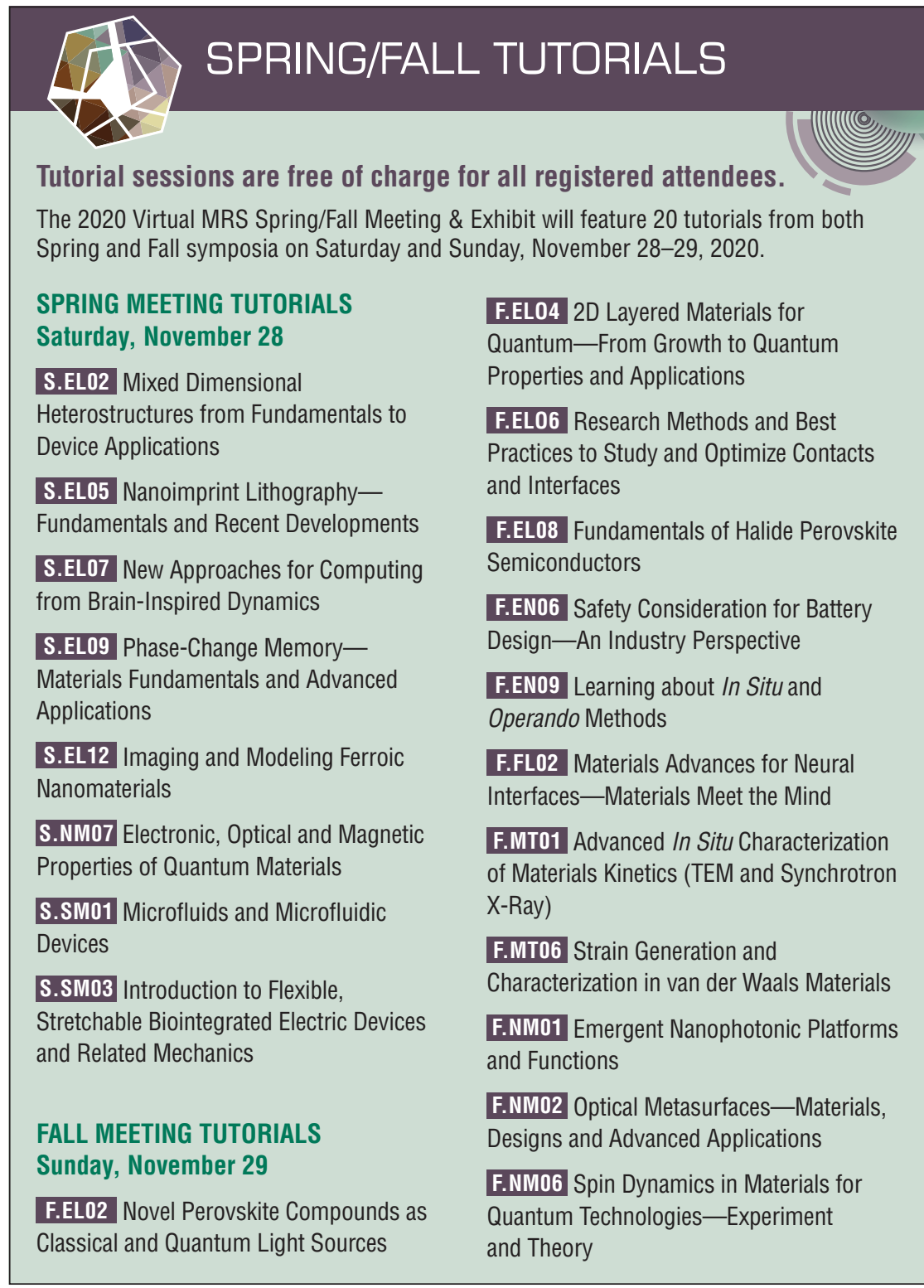

students while traveling more than 10,000 miles to visit 600 different schools in remote corners of India and Africa.

\section{MRS Postdoctoral Awards}

Edoardo Baldini (Department of Physics, Massachusetts Institute of Technology, USA). "For implementing novel laser techniques to identify and control collective excitations in quantum materials leading to major advances in the field of excitonics and phononics."

Chengwei Wang (Department of Materials Science and Engineering, University of Maryland, USA). "For developing a novel high temperature sintering technique for rapid screening and discovery of high performance ceramics for energy and other applications."

\section{Kavli Awards}

There will be a Plenary Session Featuring The Fred Kavli Distinguished Lectureship in Materials Science, and Igor Aharonovich (University of Technology Sydney, Australia) will present The Kavli Foundation Early Career Lectureship in Materials Science.

\section{MRS Bulletin Postdoctoral Publication Prize}

Ritu Raman (Massachusetts Institute of Technology, USA). "For her diverse research experience, outstanding academic 
achievements, high quality of scientific publications, extensive outreach efforts, and dedication to mentorship and professional service."

\section{Meeting events}

Science as Art Competition: The Science as Art competition is open to all registered 2020 Virtual MRS Meeting attendees. Multiple first- and second-place awards of $\$ 400$ and $\$ 200$, respectively, will be given for winning entries. Visit www.mrs.org/meetings-events/fall-meetings-exhibits/2020-mrs-spring-and-fallmeeting/science-as-art-competition for more details.

Meet the New Faculty Candidates: The "Meet the New Faculty CandidatesVirtual Session" offers an excellent opportunity for recruiters and search committees to find new faculty candidates, and networking for faculty candidates to meet one another and get feedback before their interviews. Faculty candidates registered for the MRS Meeting are invited to submit an abstract for this virtual session.

Navigating, surviving, and thriving in the challenging landscape of academia: Academia can be an isolating and emotionally turbulent environment, and this is only compounded by the current COVID crisis. How can we support ourselves, each other, and our communities? Join us for a series of speakers and small-group reflections on mental health literacy, stressors faced by academics - especially by members of marginalized communities - and creating cultural change, while learning tools and strategies for empowerment, wellbeing, and self-care.
Materials Voice: Tell your legislators why support of the physical sciences and science education is necessary - for national security, quality of life, and a strong economy. With Materials Voice, you can create personalized letters addressed to your representatives on Capitol Hill. It's essential that your voice be heard on science policy issues.

\section{Women in MS\&E-}

Keynote Lecture: Additional information will be available via the MRS website.

Meet with MRS Editors: Opportunities will be available for presenters to meet with MRS Editors, who can give input on planned or potential journal articles they are considering submitting.

Green Cards for Scientific Researchers-How to Win Your EB-1/NIW Case! Learn everything you need to know to understand the US immigration system and maximize your chances of winning a green card from Brian Getson, Esq.

Snack Chats: Six 45-minute virtual networking sessions, known as "Snack Chats," will feature discussions about career-related topics.

\section{Pre-meeting events}

FREE COVID-19 Panel Discussion on November 17: This interactive event will address how the pandemic has impacted sustainability aspects of material supply chains, including energy, environmental,

\section{F.GI01 Special Symposium}

\section{Materials Approaches for Tackling COVID-19}

Invited talks and panel discussions:

- Personal Protective Equipment and Surface Sanitization

Fensing and Diagnostic Tools

And more!

unday, November 29 overview presentation:

biology and pathology of COVID-19.

yson, Massachusetts Institute of Technology

and human health impacts of products such as personal protective equipment and batteries. It is organized by the MRS Focus on Sustainability Subcommittee, the $M R S$ Energy \& Sustainability journal, and Meeting Symposium GI01.

FREE Webinar on November 19: "Virtual Networking for Nerds: How to Network and Find Collaborators from Afar," will explore strategies for finding new collaborators. For more informatation or to register, visit www.mrs.org/webinars.

Look for additional special sneak-peak presentations and events in November leading up to the Meeting.

\section{Registration}

The deadline to preregister for the 2020 Virtual MRS Spring/Fall Meeting \& Exhibit is November 20 (11:59 pm ET). For updated information on confirmed talks and special events, visit mrs.org/ spring-fall-2020. We look forward to seeing you online!

\begin{tabular}{|c|c|c|}
\hline $\begin{array}{l}\text { REGISTRATION } \\
\text { RATES }\end{array}$ & $\begin{array}{l}\text { PREREGISTRATION } \\
\text { before 11:59 pm (ET) } \\
\text { November } 20,2020\end{array}$ & $\begin{array}{c}\text { STANDARD } \\
\text { REGISTRATION } \\
\text { after 11:59 pm (ET) } \\
\text { November } 20,2020\end{array}$ \\
\hline Meeting Registration & $\$ 425$ & $\$ 475$ \\
\hline $\begin{array}{l}\text { Meeting Registration with MRS Member } \\
\text { Discount }\end{array}$ & $\$ 250$ & $\$ 300$ \\
\hline Student Registration* & $\$ 115$ & $\$ 125$ \\
\hline $\begin{array}{l}\text { Student Registration with MRS Member } \\
\text { Discount* }\end{array}$ & $\$ 75$ & $\$ 85$ \\
\hline Retired or Unemployed & $\$ 115$ & $\$ 125$ \\
\hline
\end{tabular}

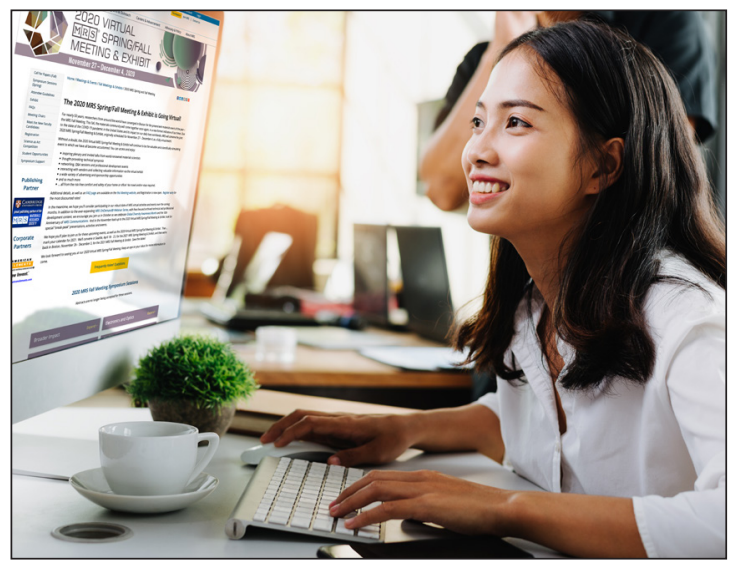

